\title{
RESERVA DO POSSÍVEL E VEDAÇÃO DE RETROCESSO COMO LIMITE À ALTERAÇÃO DOS DIREITOS SOCIAIS NO BRASIL: EXTENSÃO DO MODELO DE FIXAÇÃO DE PARÂMETROS NO DIREITO À SAÚDE PARA DIREITOS PREVIDENCIÁRIOS
}

\author{
Cleber Sanfelici Otero ${ }^{1}$ \\ Adriano Carlos Ravaioli ${ }^{2}$
}

\section{RESUMO:}

No artigo, há uma descrição da evolução dos direitos sociais até inclusão nas Constituições no Século XX, explanando sobre suas principais características de fundamentalidade e aplicabilidadade. Diante dos limites econômico-financeiros existentes nos Estados para a efetivação desses direitos, explana-se acerca da Reserva do Possível como uma barreira para aplicá-los. Por fim, discorre-se acerca da Vedação ao Retrocesso como limite à Reserva do Possível e instrumento à efetivação dos direitos sociais. É usado o método dedutivo e, mediante comparação com o direito à saúde, é sugerido o estabelecimento de parâmetros para uma reforma previdenciária.

PALAVRAS-CHAVE: Direitos fundamentais; Direitos sociais; Reserva do Possível; Vedação ao retrocesso; Escassez de recursos.

\section{THE PROVISO OF THE POSSIBLE AND THE NON-REGRESSION CLAUSE AS A LIMIT OF SOCIAL RIGHTS IN BRAZIL: EXTENSION OF THE MODEL FOR SETTING PARAMETERS ON HEALTH RIGHTS FOR PENSION RIGHTS}

\begin{abstract}
:
In the article, there is a description of the evolution of social rights until its inclusion in Constitutions in the 20th Century, explaining its main characteristics of fundamental and applicability. Given the economic-financial limits in the states for the realization of these rights, the Proviso of the Possible is explored as a barrier to their application. There is a discussion about the prohibition of setback as a limit to Reserve of Possible and an instrument to accomplish social rights. The deductive method is used and, by comparison with health right, the establishment of parameters for social security rights is suggested.
\end{abstract}

KEYWORDS: Fundamental rights; Positive rights to social welfare; Proviso of the Possible; Non-regression clause; Scarcity of resources.

\footnotetext{
${ }^{1}$ Doutor e Mestre em Direito Constitucional pela ITE (Bauru/SP). Professor na Pós-graduação Stricto Sensu (Mestrado e Doutorado) em Ciências Jurídicas e na Graduação em Direito da UNICESUMAR (Maringá/PR). Professor na Especialização em Direito Previdenciário da UEL (Londrina/PR). Juiz Federal.

${ }^{2}$ Mestrando em Ciências Jurídicas pela UNICESUMAR (Maringá/PR). Advogado.
} 


\section{INTRODUÇÃO}

Os direitos fundamentais - dentre eles os sociais - perfazem o cerne do ordenamento jurídico pátrio, sendo basicamente o fundamento da Constituição da República Federativa do Brasil de 1988. No que se refere especificamente aos direitos sociais, a Constituição absorveu de forma pródiga esses direitos criados no contexto internacional pelos movimentos sociais do século XX e a busca por sua efetivação configura um desafio ao Estado Democrático de Direito.

Existem barreiras para a efetivação dos direitos sociais, principalmente diante da escassez de recursos materiais, sendo necessário analisar a forma como o Estado aplica e administra as verbas públicas no intuito de garantir a efetivação desses direitos.

Em face da existência dessas barreiras, inúmeros são os estudos sobre a questão, graças aos quais já se chegou a uma compreensão razoável de que os direitos sociais têm um custo estatal considerável e de que os recursos disponíveis não são suficientes para realizar todos os direitos de forma plena, o que faz com que agentes do Poder Legislativo, do Poder Executivo e até do Poder Judiciário tenham de fazer "escolhas trágicas" com relação às políticas públicas a serem adotadas (OLSEN, 2008, p. 187).

Por conta das dificuldades econômicas, a doutrina e a jurisprudência buscaram estabelecer critérios para definir as situações em que estes direitos merecem uma prestação pública, bem como os casos em que cabem restrições. À dificuldade econômica e ao decorrente estabelecimento do conjunto de critérios para a prestação de direitos sociais tem-se denominado reserva do possível.

$\mathrm{Na}$ área da saúde, como critérios, por exemplo, tem-se o estabelecimento de que os tratamentos pioneiros sem comprovação de eficácia, ou mais dispendiosos que outros já disponibilizados, não devem ser custeados pelo Estado.

No Direito Previdenciário, ainda não há balizas fixadas na matéria, mas, em razão da Reforma da Previdência, a questão deve e merece ser debatida, porquanto a mudança nos critérios definidos para a concessão de benefícios certamente trará retrocesso com relação a direitos.

Com exploração fundada na análise na literatura jurídica na matéria, usa-se o método de abordagem dedutivo, a partir das gerais características dos direitos fundamentais à identificação dos direitos sociais como espécie daqueles, bem como dos problemas 
decorrentes da escassez de recursos para prestá-los. O método de procedimento comparativo é empregado para verificar os avanços já atingidos acerca dos temas da reserva do possível e da vedação do retrocesso na área da saúde para identificar como os critérios também podem ser utilizados em Direito Previdenciário.

\section{DIREITOS SOCIAIS COMO DIREITOS FUNDAMENTAIS}

No curso da evolução histórica, foram formadas gerações de direitos que não se superam, mas convivem entre si. Os primeiros direitos fundamentais, chamados de direitos fundamentais de primeira geração, voltavam-se contra a opressão do monarca - ou do Estado -, preconizando uma espécie de conduta passiva do poder absoluto ou mesmo uma não conduta, de forma que o governante ou agentes do Estado se abstivesse de oprimir, de usar um poder absoluto em desfavor do indivíduo. Esses primeiros direitos buscavam a liberdade do indivíduo perante o poder absoluto e, por estarem voltados a uma abstenção do Estado, por se efetivarem com uma inatividade estatal, eram classificados como direitos negativos.

Por outro lado, os direitos sociais trazem, como característica mais marcante, o fato de que são direitos que pressupõem uma conduta ativa por parte do ente estatal, ou seja, só se realizam mediante a atuação do Estado, o que lhes confere a característica de positivos. A intervenção estatal torna-se necessária para que haja a prestação de direitos diretamente pelo próprio Estado ou para que haja a realização de direitos por determinação aos particulares, mas com fiscalização pública:

Daí a problemática dos direitos sociais que, ao contrário do que a teoria liberal defendia, não postula a abstinência estadual, antes exige uma intervenção pública estritamente necessária à realização desses direitos; a intervenção estadual é concedida não como um limite, mas como um fim do Estado. (CANOTILHO, 1991, p. 159)

Acerca dos direitos fundamentais sociais, há uma função de prestação estatal que exige uma atuação muito maior dos poderes públicos, de modo a ampliar as obrigações estatais com uma correspondente cobrança tributária mais elevada dos particulares, em um processo que leva à ampliação dos poderes estatais:

É supérfluo acrescentar que o reconhecimento dos direitos sociais suscita, além do problema da proliferação dos direitos do homem, problemas bem mais difíceis de 
resolver no que concerne àquela prática de que falei no início: é que a proteção destes últimos requer uma intervenção ativa do estado, que não é requerida pela proteção dos direitos de liberdade, produzindo aquela organização dos serviços públicos de onde nasceu até mesmo uma nova forma de Estado, o Estado Social. Enquanto os direitos de liberdade nascem contra o superpoder do Estado - e, portanto, com o objetivo de limitar o poder - os direitos sociais exigem, para sua realização prática, ou seja, para a passagem da declaração puramente verbal à sua proteção efetiva, precisamente o contrário, isto é, a ampliação dos poderes do Estado. (BOBBIO, 2004, p. 272)

Os direitos sociais passaram a figurar como fins a serem perseguidos por esse novo modelo de Estado que começara a surgir, o Estado Social de Direito. Para Celso Lafer (1988, p. 227), essa complementação dos direitos de primeira geração deve-se ao legado do socialismo, por meio das reivindicações dos menos favorecidos de "participar do 'bem-estar social' entendido como os bens que os homens, através de um processo coletivo, vão acumulando no tempo". No entanto, é preciso referir que os direitos sociais não se limitam às prestações positivas, mas também abrangem as chamadas "liberdades sociais", a exemplo do direito de greve, direito a férias, dentre outros, conforme lição de Ingo Sarlet (2012, p. 55).

Segundo Canotilho (2003, p. 272-273), adotando as características de fundamentalidade identificadas por Robert Alexy, os direitos fundamentais possuem proteção em sentido formal e material. A fundamentalidade formal encontra-se associada à constitucionalização e resulta em alguns aspectos que, sendo adaptados ao Direito Constitucional pátrio por Ingo Sarlet (2012, p. 74-75), seriam: a) os direitos fundamentais são colocados em grau superior a todo ordenamento jurídico, possuindo natureza supralegal; b) incluem-se no rol de cláusulas pétreas, submetendo-se aos limites formais e materiais de reforma constitucional; c) trata-se de normas dotadas de imediata aplicabilidade, vinculando as entidades públicas e privadas.

Segundo a fundamentalidade material, o conteúdo dos direitos fundamentais constitui a estrutura básica do Estado e da sociedade. A fundamentalidade material pode não estar associada à ideia de fundamentalidade formal e à Constituição escrita (CANOTILHO, 2003, p. 373). Porém, é por meio do Direito Constitucional positivo que a fundamentalidade material autoriza a abertura da Constituição a outros direitos fundamentais não incluídos em seu texto (apenas materialmente formais), assim como a direitos situados fora do catálogo, mas dentro da Constituição Federal (SARLET, 2012, p. 75). Assim, é em virtude da fundamentalidade material que mesmo direitos fora do catálogo do art. $5^{\circ}$ da Constituição Federal - direitos sociais - são reconhecidos como fundamentais. 
Vale ressaltar que direitos sociais, ante a complementaridade entre os direitos fundamentais, envolvem aspectos muitas vezes relacionados com direitos individuais, como na relação entre o direito à saúde e os direitos à vida e à integridade física e psíquica.

\subsection{Desenvolvimento histórico}

Como visto, os direitos sociais são posteriores aos direitos civis e políticos, preconizados no Estado Liberal, onde se desvendaram os chamados direitos de liberdade, os quais constituíram a chamada primeira geração ou dimensão de direitos fundamentais.

A partir da daí, fala-se numa segunda dimensão de direitos, os direitos sociais, positivados no contexto do Estado Social de Direito. Entretanto, não há unanimidade no que tange à evolução em gerações dos direitos fundamentais, conforme registra Gerardo Pisarello (2011, p. 21), para quem "essa representação assenta em pressupostos que tendem a ser restritivos, excludentes e deterministas, e que justificariam, em última análise, uma proteção desvalorizada dos direitos sociais".

Os direitos sociais foram vistos como um requisito indispensável a dar conteúdo material aos direitos civis e políticos, enquanto estes atuaram como instrumentos indispensáveis para assegurar os direitos sociais (PISARELLO, 2011, p. 22).

Em igual sentido, colige-se a lição de Norberto Bobbio (2004, p. 226-227), como se infere:

\footnotetext{
A mais fundamentada razão da sua aparente contradição, mas real complementaridade, com relação aos direitos de liberdade, é a que vê nesses direitos uma integração dos direitos de liberdade, no sentido de que eles são a própria condição do seu exercício efetivo. Os direitos de liberdade só podem ser assegurados garantindo-se a cada um o mínimo de bem-estar econômico que permite uma vida digna. (BOBBIO, 2004, p. 226-227)
}

Classicamente, tem-se que o surgimento dos direitos sociais ocorreu no contexto da transição entre o Estado Liberal e o Estado Social, tendo como marco fundamental a Revolução Industrial ocorrida no século XIX, a partir da qual houve a positivação legal desses direitos em face de reivindicações da classe trabalhadora e, no princípio do século seguinte, no plano constitucional, com a Constituição mexicana de 1917 e a Constituição alemã de Weimar de 1919. 
O modelo liberal de Estado tinha como características o não intervencionismo, atuando apenas na proteção das liberdades individuais. Com o decorrer do tempo, a ausência de controle sobre os efeitos socialmente indesejáveis da livre atuação dos agentes econômicos privados provocou imensas desigualdades sociais, levando a grande maioria da população a viver em condições de miserabilidade e degradação, sem efetiva possibilidade de exercício de grande parte dos direitos, os quais, nesta condição, eram reduzidos a direitos meramente formais (JOSKOWICZ, 2010). Esse contexto conduziu à concepção do Estado Social, caracterizado pela postura de intervenção na ordem econômica e social em prol da promoção do bem-estar dos cidadãos.

Na mesma esteira do que leciona Pisarello, segundo Kelbert (2011, p. 22) “é possível detectar uma rica pré-história, tanto de políticas institucionais dirigidas a resolver situações de pobreza e exclusão social como de lutas pela subsistência e a segurança material". Refere, ainda, que essa pré-história é bem anterior ao surgimento do Estado Moderno e se assemelha a algumas reivindicações atuais em sede direitos sociais, conforme se vê: "Tanto na antiguidade como no período medieval, de fato existiram diferentes mecanismos institucionais, ainda que não necessariamente estatais, orientados a atenuar situações propagadas de pobreza e a assistir grupos mais necessitados.” (KELBERT, 2011, p. 22).

Pisarello (2011, p. 22) aponta previsões de cunho social na Declaração de Independência dos Estados Unidos de 1776, na qual se encontravam ecos da experiência igualitária. Um pouco anterior, o Bill of Rights do estado norte-americano da Virgínia é considerado a primeira positivação abrangente e com força constitucional dos direitos fundamentais em sentido moderno (KELBERT, 2011, p. 22).

Por sua vez, em França, a Constituição jacobina de 1793 também previu direitos sociais, inclusive o direito ao trabalho, conforme leciona Ledur (2009, p. 71). Já na Constituição de 1795 , os direitos sociais perderam força e não foram mais acolhidos, fato que também aconteceu nas constituições napoleônicas.

Já no século XX, as referências mais frequentes acerca da positivação dos direitos sociais apontam para a Constituição mexicana de 1917. Comparato (2004, p. 174) ensina que a importância histórica desse documento se deveu ao fato de que foi a primeira Constituição a atribuir aos direitos trabalhistas a qualidade de direitos fundamentais, ao lado das liberdades individuais e dos direitos políticos. 
Em seguida, ocorreu a Revolução Comunista de 1917, após a qual a República Soviética Russa proclamou, em janeiro de 1918, a Declaração do Povo Trabalhador e Explorado.

Na sequência, na Alemanha, a Constituição de Weimar de 1919 também incluiu os direitos sociais no seu texto.

Essas Constituições figuram como referências no constitucionalismo social, pois foram as primeiras a acrescentar um viés marcadamente social à Constituição.

Merece especial destaque, no presente tópico, a Declaração Universal dos Direitos Humanos, aprovada pela Assembleia Geral das Nações Unidas em 1948, após as barbáries cometidas durante a Segunda Guerra Mundial. A declaração foi aprovada por unanimidade, embora, segundo Fábio Konder Comparato, diversos países se abstiveram de votar, dentre eles União Soviética, Ucrânia, Tchecoslováquia, Polônia, Iugoslávia, Arábia Saudita e África do Sul (COMPARATO, 2004, p. 223).

Deve-se mencionar ainda as constituições portuguesa e espanhola, as quais se destacam em razão de evidente caráter social, o que se depreende da simples leitura de seus respectivos preâmbulos.

\subsection{Os direitos sociais na história constitucional do Brasil}

$\mathrm{Na}$ história constitucional brasileira, poucos direitos sociais constaram da Constituição do Império do Brasil de 1824. A Constituição de 1824 foi influenciada pelas ideias liberais e pelo constitucionalismo em voga na Europa, tendo sido a primeira Constituição a catalogar direitos fundamentais. Os direitos sociais compunham o rol do art. 179: o direito aos socorros públicos (inciso XXXI) e o direito à instrução primária gratuita a todos os cidadãos (inciso XXXII). O inciso XXIV desse artigo contemplava a liberdade de profissão, desde que não se opusesse aos costumes públicos, à segurança e à saúde dos cidadãos.

A Constituição de 1891, na Seção II, tratava da Declaração de Direitos, em que o art. 72 , § 24, previa o livre exercício de qualquer profissão moral, intelectual e industrial, porém sem a restrição contida na Constituição precedente (BARBALHO, apud KELBERT, 2011, p. 22). 
A Constituição da República dos Estados Unidos do Brasil, de 16 de julho de 1934, no Título II, da Declaração de Direitos, mais especificamente no seu Capítulo II, intitulado Dos Direitos e Garantias Individuais, previu, no art. 113, inciso XIII, o direito ao livre exercício de qualquer profissão. Observa-se que essa Constituição contemplou um primeiro esboço da assistência social, no entanto excluiu o direito à aposentadoria (LEDUR, 2009, p. 72).

Já na Constituição de 1937, na parte destinada aos "Direitos e Garantias Individuais", o art. 122 manteve o direito à liberdade de escolha da profissão, mas instituiu a censura no inciso XV, alínea "a". Nos arts. 135 a 155, estavam contidos diversos direitos relacionados ao trabalho, o qual era considerado um "dever social”. O art. 137 continha os preceitos a ser observados na legislação trabalhista, dentre os quais o salário mínimo, assistência médica e higiênica ao trabalhador e à gestante e a instituição de seguros de velhice, invalidez e de vida para os casos de acidente de trabalho.

A Constituição de 1946 ampliou sobremaneira a previsão dos direitos sociais, voltando a introduzir um título denominado "Da Ordem Econômica e Social”. No art. 157, foram arrolados diversos direitos sociais relativos aos trabalhadores. Os novos direitos sociais introduzidos foram: salário mínimo capaz de satisfazer conforme as condições de cada região, as necessidades normais do trabalhador e de sua família; proibição de diferença de salário para um mesmo trabalho por motivo de idade, sexo, nacionalidade ou estado civil; repouso semanal remunerado; assistência aos desempregados; previdência, mediante contribuição da União, do empregador e do empregado, em favor da maternidade e contra as consequências da doença, da velhice, da invalidez e da morte; direito de greve (art. 158); e liberdade de associação profissional e sindical (art. 159). Nos dizeres de Ledur (2009, p. 76), “mediante a Constituição de 1946, o Brasil reencontra-se com a democracia”.

A Constituição de 1967 previu um capítulo sobre direitos e garantias individuais (art. 153) e um dispositivo (art. 165) com um rol de direitos sociais dos trabalhadores, para a melhoria de suas condições sociais. No texto anterior à Emenda 01/1969, previu uma série de direitos que visavam à melhoria de sua condição social, tais como previdência social e o direito de aposentadoria para a mulher aos trinta anos de trabalho com salário integral. A Emenda Constitucional $n^{\circ}$ 01/1969 alterou praticamente todo o texto anterior, mas, em relação aos direitos sociais, praticamente não houve modificações no que diz respeito aos direitos dos trabalhadores e à educação (KELBERT, 2011, p. 31). 
Com relação à Constituição Federal de 1988, de forma pioneira, erigiu os direitos sociais à categoria de direitos fundamentais ao incluí-los expressamente no Título II, "Dos Direitos e Garantias Fundamentais" (KELBERT, 2011, p. 33). Esse caráter de fundamentalidade, reconhecido a direitos que antes apenas se enquadravam na categoria de direitos econômicos e sociais, pode ser entendido como um compromisso do legislador constituinte em construir uma sociedade um pouco mais equilibrada, dadas as gritantes diferenças sociais que sempre foram e ainda são características das sociedade brasileira.

\section{DA RESERVA DO POSSÍVEL}

Os direitos sociais, como os direitos fundamentais em geral, abrangem tanto direitos a prestações (positivos) como direitos de defesa (negativos). As normas consagradoras dos direitos de defesa, de regra, já receberam do Constituinte a suficiente normatividade, independem de concretização legislativa e, por isso, são mais facilmente reconhecidas como de aplicabilidade imediata e plena eficácia. A esses direitos não se aplicam os argumentos que restringem a aplicabilidade imediata dos direitos a prestações que são a reserva do possível e a ausência de legitimação dos tribunais para definirem o conteúdo e o alcance da prestação (SARLET, 2012, p. 274 e 277).

Todos os direitos fundamentais, inclusive os direitos de defesa, tidos como negativos, implicam algum custo e devem ser considerados no orçamento (HOLMES; SUNSTEIN, 1999, p. 22 e 35-48). Os custos não se limitam apenas aos direitos de cunho social prestacional. Aqueles direitos que não implicam uma prestação por parte do Estado (direitos de defesa ou negativos) possuem apenas uma relativa neutralidade econômica e, portanto, sua efetivação depende menos de dispêndio de dinheiro público, ao menos de forma direta, muito embora ela exista. A título ilustrativo, não é possível garantir os direitos individuais à segurança e à propriedade sem uma estrutura jurídica, policial e judiciária, de maneira que o Estado necessita empregar recursos, obtidos com tributação, logo, em última análise, os direitos individuais também custam, pois são dependentes da existência de uma certa estrutura para serem protegidos se acaso afrontados (OTERO, 2011, p. 278). Já com relação aos direitos sociais a prestações, sua efetivação depende da alocação direta de recursos financeiros, e não apenas em termos estruturais. 
Quando o Estado deixa de fornecer ou prestar aquilo que lhe cabe, o cidadão pode recorrer ao Poder Judiciário para a realização de seus direitos de natureza prestacional. Com isso, e em virtude da reduzida capacidade econômico-financeira do ente público, a doutrina e a jurisprudência buscam estabelecer critérios que pudessem orientar as situações nas quais deve ou não haver a prestação pública de direitos. Com este conjunto de critérios ante a dificuldade econômica estatal, tem-se uma adaptação da reserva do possível no Brasil, que tem obtido especial importância no campo dos direitos sociais por conta do nítido aspecto prestacional e da consequente relevância econômica dessa classe de direitos.

O Estado não se encarrega apenas de prestar direitos sociais, mas de criar direitos para as pessoas ao estabelecer obrigações para outros particulares:

\footnotetext{
Estes direitos - aliás, como todo direito fundamental que tem uma dimensão prestacional a ser observada pelos poderes públicos, ainda que exclusivamente de proteção - preveem a realização de condutas materiais pelo Estado, como educação, saúde, previdência. Significa dizer que a obrigação prevista na norma depende de uma atividade a ser prestada pelo Estado que, intervindo no mundo dos fatos, altereo, fornecendo bens jurídicos antes inexistentes para o titular daquele direito. Nestas condições, a dimensão fática de viabilidade de realização do direito assume uma importância especial. (OLSEN, 2008, p. 201)
}

A reserva do possível teve origem no julgamento do caso "numerus clausus" pelo Tribunal Constitucional Federal da Alemanha, em 1972. Discutia-se o acesso ao curso de medicina e a compatibilidade de certas regras legais que restringiam esse acesso ao ensino superior, bem como a liberdade de escolha da profissão. O Tribunal decidiu que a prestação exigida do Estado deve corresponder ao que o cidadão pode razoavelmente exigir da sociedade, e entendeu que não seria razoável impor ao Estado a obrigação de acesso a todos os que pretendessem cursar medicina. A reserva do possível, nesse caso, relacionou-se à exigência de prestações dentro do limite de razoabilidade, e não da escassez de recursos como foi interpretada no Brasil (OLSEN, 2008, p. 6).

Em especial, merece destaque o fato de que, no caso alemão, o Estado havia adotado todas as providências ao seu alcance para fornecer ensino em nível superior a seus cidadãos, inclusive mediante programas de expansão, embora ainda não fossem suficientes. No Brasil, o Estado não faz todo o possível para cumprir os mandamentos constitucionais, gastando vultosos recursos com obrigações outras que não direitos fundamentais (OLSEN, 2008, p. 223). 
A leitura diversa da reserva do possível decorre da grande diferença socioeconômica entre a Alemanha e o Brasil:

\begin{abstract}
Devemos lembrar que os integrantes do sistema jurídico alemão não desenvolveram seus posicionamentos para com os direitos sociais num Estado de permanente crise social e milhões de cidadãos socialmente excluídos. Na Alemanha - como nos países centrais - não há um grande contingente de pessoas que não acham vagas nos hospitais mal equipados da rede pública; não há a necessidade de organizar a produção e distribuição de alimentação básica a milhões de indivíduos para evitar sua subnutrição ou morte; não há altos números de crianças e jovens fora da escola; não há pessoas que não conseguem sobreviver fisicamente com o montante pecuniário de assistência social que recebem, etc. (KRELL, 2002, p. 108-109)
\end{abstract}

No caso de países em desenvolvimento, como o Brasil, a reserva do possível tem aplicação em situações mais extremas, como o direito à vida, o que deve levar ao cuidado de não reduzir o texto constitucional a uma mera carta de recomendações (BREUS, 2007, p. 234).

Não obstante, adotadas as necessárias cautelas, não há como se negar a validade do instituto para o equacionamento de questões relativas à exigibilidade dos direitos sociais. Em virtude da ausência de condições financeiras de garantir integralmente todos os direitos sociais, cabe ao ente estatal fazer escolhas, estabelecendo as prioridades e critérios a ser seguidos por meio da implementação de políticas públicas que consistem na destinação do orçamento público para determinados fins, apesar da barreira da reserva do possível em face à limitação financeira do Estado.

Para Olsen (2008, p. 212), a reserva do possível "é uma condição de realidade que determina a submissão dos direitos fundamentais prestacionais aos recursos existentes”. Poderia, assim, ser analisada no campo da lógica e da disponibilidade de recursos materiais. No primeiro caso, a reserva do possível impediria que o interessado exigisse do Estado prestações logicamente impossíveis ou absurdas, como o fornecimento de medicamento para cura de doença ainda incurável.

Em relação à existência de recursos materiais, por consequência, a reserva do possível somente impediria a exigência de prestações do Estado quando não houvesse disponibilidade fática (do bem ou dos meios necessários à sua realização) ou jurídica (possibilidade jurídica, incluída a capacidade de dispor) dos recursos para sua efetivação (OLSEN, 2008, p. 204-205). 
O instituto privilegia e encontra amparo no princípio democrático e de separação de poderes, alinhando-se à construção teórica desenvolvida na Alemanha a partir do caso numerus clausus, em que

[...] os direitos sociais a prestações materiais dependem da real disponibilidade de recursos financeiros por parte do Estado, disponibilidade esta que estaria localizada no campo discricionário das decisões governamentais e parlamentares, sintetizadas no orçamento público. (SARLET; FIGUEIREDO, 2010, p. 29)

Não se pode deixar de fazer a devida distinção entre inexistência de recursos e escolha política de onde esses recursos serão alocados, isto é, a escolha alocativa de recursos. Ainda que a Constituição não determine o modo de aplicação e o montante de recursos a ser direcionado à realização de cada direito social - exceto nas áreas de saúde e educação -, é certo que ela conferiu tratamento prioritário aos direitos sociais, diante da obrigatoriedade de se realizar uma interpretação constitucional que leve em consideração o fundamento de todo o sistema constitucional, qual seja, a proteção aos direitos fundamentais do indivíduo diante de sua estreita ligação com o princípio da dignidade humana, que é um dos objetivos primordiais do Estado brasileiro.

Dessa forma, caso os direitos sociais não tenham seu caráter prioritário devidamente considerado na formulação ou na execução orçamentária, ganha espaço a atuação da força normativa da Constituição em prol desses direitos, e perde a oponibilidade fundada na reserva do possível (CAYRES, 2017).

Torna-se necessário verificar se há recursos econômicos do Estado para, em seguida, alocá-los em conformidade com prioridades de maneira a assegurar o mínimo necessário, por vezes com critérios, ainda que haja discricionariedade administrativa:

Logo, há que se diferenciar entre o que não é possível porque não há, comprovadamente, meios suficientes, mesmo depois de atendidas as normas constitucionais que determinam alocação de recursos, e o que não é possível porque os meios suficientes foram alocados para outras prioridades. [...] Para tanto, a própria Constituição fornece parâmetros, a serem respeitados, como já analisado. Uma escolha alocativa de recursos, dentro da chamada discricionariedade administrativa, deverá sempre respeitar os mínimos já fixados na Constituição, bem como as prioridades por ela enumeradas. Não se trata de aprisionar as decisões políticas, mas condicioná-las em conformidade com os valores presentes como um todo na sociedade - e neste diapasão, todos os direitos fundamentais merecem satisfação. (OLSEN, 2008, p. 210-211) 
O que se constata, na realidade, é um completo descaso com a efetivação dos direitos sociais, notado por gastos desnecessários, pela falta de planejamento ou má gestão das verbas públicas (OTERO, 2011, p. 302), conjuntamente com a criação de políticas públicas insuficientes para atender à demanda da população. Esses desvios de interesses (CAYRES, 2017), bem como a ausência de recursos financeiros, no entanto, não podem ter o condão de comprometer o mínimo necessário para a existência digna da pessoa humana (OTERO, 2011, p. 302).

Não se pode permitir, portanto, que o argumento da reserva do possível constitua uma barreira para que o Estado deixe de promover e realizar direitos fundamentais, sejam eles direitos sociais ou não.

\section{VEDAÇÃO AO RETROCESSO SOCIAL}

A proibição de retrocesso social é decorrência do princípio da democracia econômica social, porquanto direitos sociais já alcançados ou conquistados passam a figurar, ao mesmo tempo, como garantia institucional e direito subjetivo:

[...] quer dizer-se que os direitos sociais e econômicos (ex.: direito dos trabalhadores, direito à assistência, direito à educação), uma vez obtido um determinado grau de realização, passam a constituir, simultaneamente, uma garantia institucional e um direito subjectivo. A "proibição de retrocesso social" nada pode fazer contra as recessões e crises econômicas (reversibilidade fática), mas o princípio em análise limita a reversibilidade dos direitos adquiridos (ex.: segurança social, subsídio de desemprego, prestações de saúde), em clara violação do princípio da protecção da confiança e da segurança dos cidadãos no âmbito económico, social e cultural, e do núcleo essencial da existência mínima inerente ao respeito pela dignidade da pessoa humana. (CANOTILHO, 2003, p. 338-339)

Manifesta-se isso de duas maneiras: por um lado, serve para impedir a supressão de direitos já conquistados; e, por outro, surge como uma obrigação de empenho por uma política afinada com os direitos concretizados (CANOTILHO, 2003, p. 474).

Para Barroso (2006, p. 158), pelo princípio da vedação ao retrocesso entende-se que "se uma lei, ao regulamentar um mandamento constitucional instituir determinado direito, ele se incorpora ao patrimônio jurídico da cidadania e não pode ser absolutamente suprimido".

Relacionando a vedação ao retrocesso com a reserva possível, temos que essa, quando utilizada como argumento para supressão de alguma política pública que já logrou 
concretizar direitos sociais, poderá dar causa a uma violação ao princípio da proibição do retrocesso. Nesse sentido, dada a dupla dimensão dos direitos fundamentais, pode-se remeter aqui à dimensão subjetiva, no sentido de proteger posições subjetivas já consolidadas. Por outro lado, também se pode invocar a dimensão objetiva, que obriga os poderes estatais a se empenharem no sentido da máxima concretização dos direitos sociais, de modo que medidas que atentem contra isso representam um retrocesso (KELBERT, 2011, p. 97).

Tendo em vista o caráter relativo inerente a todos os princípios, eventuais ajustes operados em sede de direitos sociais e que possam apresentar um retrocesso deverão ser devidamente justificados.

A redução ou limitação de direitos sociais não pode vir a atingir, em face da teoria limite dos limites, o núcleo essencial do direito fundamental, principalmente se restar atingida a dignidade humana:

\begin{abstract}
Mediante a supressão pura e simples do próprio núcleo essencial legislativamente concretizado de determinado direito social (especialmente dos direitos sociais vinculados ao mínimo existencial) estará sendo afetada, em muitos casos, a própria dignidade da pessoa, o que desde logo se revela inadmissível, ainda mais em se considerando que na seara das prestações mínimas (que constituem o núcleo essencial mínimo judicialmente exigível dos direitos a prestações) para uma vida condigna não poderá prevalecer até mesmo a objeção da reserva do possível e a alegação de uma eventual ofensa ao princípio democrático e da separação dos poderes. (SARLET, 2012, p. 215)
\end{abstract}

Assim, o argumento da reserva do possível como fundamento a medidas (ainda que de caráter pro futuro) que importem em um retrocesso no campo das conquistas sociais não poderá ter valor sem uma justificativa sintonizada com todo o sistema constitucional, sob pena de violação do mínimo em conteúdo exigível quando em causa a concretização de direitos sociais (KELBERT, 2011, p. 98).

\title{
5 PARAMETRICIDAde do DIREITO À SAÚde COMO MODELO PARA O ESTABELECIMENTO DE CRITÉRIOS PARA OUTROS DIREITOS SOCIAIS
}

Acerca do direito à saúde, o Supremo Tribunal Federal (STF) convocou audiência pública para ouvir profissionais da área e, em seguida, o Plenário decidiu estabelecer parâmetros para o tratamento jurídico da questão relativa à concessão de medicamentos por parte do Sistema Único de Saúde (SUS), com precedente estabelecido em processo no qual o Poder Público escusou-se de fornecer medicamento sob a alegação de ser fármaco não 
registrado na Agência Nacional de Vigilância Sanitária (ANVISA), não produzir efeito benéfico comprovado e ter um alto custo (OTERO, 2011, p. 339-340). Condenou-se, no entanto, o Poder Público a fornecê-lo, primeiramente pelo fato de que o medicamento passou a ser registrado na ANVISA, depois porque sua eficácia restou demonstrada na instrução processual e, por fim, em razão do alto custo de um tratamento registrado na ANVISA não ser suficiente para impedir o seu fornecimento pelo Poder Público:

EMENTA: Suspensão de Segurança. Agravo Regimental. Saúde pública. Direitos Fundamentais sociais. Art. 196 da Constituição. Audiência Pública. SISTEMA ÚNICO DE SAÚDE - SUS. Políticas públicas. Judicialização do direito à saúde. Separação de poderes. Parâmetros para solução judicial dos casos concretos que envolvem direito à saúde. Responsabilidade solidária dos entes da Federação em matéria de saúde. Fornecimento de medicamento: Zavesca (miglustat). Fármaco registrado na ANVISA. Não comprovação de grave lesão à ordem, à economia, à saúde e à segurança públicas. Possibilidade de ocorrência de dano inverso. Agravo regimental a que se nega provimento. (BRASIL, 2010a)

O voto do Ministro Gilmar Mendes proferido neste julgado foi irretocável, em análise não apenas jurídica, mas intersistemática com a economia, a saúde e a medicina, com teor que ora resumimos em face da relevância: a) O Poder Judiciário deve observar, casuisticamente, se já há políticas públicas, pois, se elas existirem, o juiz não estará criando direito por meio de ativismo judiciário; b) Se houver políticas do SUS, deve-se distinguir se a ausência de prestação decorre de omissão legislativa ou administrativa, de uma decisão administrativa de não fornecê-la ou, ainda, de uma vedação legal à sua dispersão; c) Há obrigação do Poder Público de fornecer os remédios registrados na ANVISA por força do disposto na Lei 6.360/76, pois a referida Agência atesta a segurança e a eficácia do uso dos medicamentos, além de estabelecer o seu custo em razão de seu benefício, valorado de forma a não superar o preço de um produto similar já existente; d) Por estar o SUS atrelado à "Medicina com base em evidências" e em razão do princípio do acesso universal e igualitário, não se pode obrigar o Poder Público a fornecer tratamentos sem eficácia comprovada, nem a oferecer o tratamento escolhido pelo paciente em detrimento de outros dispostos pelo SUS e nem a conceder tratamento que possa gerar grave lesão à ordem administrativa a ponto de comprometer o próprio sistema e a prejudicar a parcela da população mais prejudicada; e) É também necessário diferenciar se os tratamentos não fornecidos pelo Estado são puramente experimentais ou se simplesmente ainda não foram testados pelo SUS, naqueles casos não se podendo obrigar o órgão público a fornecê-los, enquanto nestes, em face da rápida evolução 
da medicina, muitas vezes fica difícil avaliar a tempo as novidades no setor, de maneira que se torna necessária a abertura de instrução probatória para avaliar a eficácia do tratamento em relação a determinados pacientes no caso concreto.

Em outro processo, o STF chegou a decidir, até mesmo, que a lesão aos cofres públicos em função do preço elevado do remédio, ao custo anual de $\mathrm{R} \$ \mathbf{9 2 0 . 0 0 0 , 0 0}$ para um paciente, não poderia ser alegada em função da existência de uma Política de Dispensação de Medicamentos Excepcionais a garantir justamente o acesso à população acometida por enfermidades raras (BRASIL, 2010b).

Destarte, como parâmetro, cabe correlacionar a determinação de prestar serviço público na área da saúde com a responsabilidade civil estatal e, tal qual no afastamento da responsabilidade subjetiva após o Estado comprovar que foi diligente, perito e prudente, o Poder Público também deve ser liberado de cumprir uma obrigação se demonstrar que a nãoprestação de um serviço público de saúde deve ocorrer em virtude do remédio não ser registrado na ANVISA, não ter eficácia comprovada, ou em razão de poder vir a causar dano, ou porque outro tratamento mais barato e eficaz é fornecido pelo SUS ou, ainda, pela possibilidade de falência do sistema em razão de um custo absurdamente elevado (OTERO, 2011, p. 342).

Os parâmetros estabelecidos pelo STF são relevantes para orientação não apenas em matéria de fornecimento de medicamentos na área da saúde, mas também para outros direitos sociais.

Com relação à previdência social, não há dúvida de que houve um avanço quanto ao estabelecimento de direitos e de que a extinção deles pode acarretar retrocesso, porém é preciso observar que os critérios para o direito à aposentadoria foram definidos em consideração à expectativa de vida em uma época em que os brasileiros viviam bem menos, algo que é de conhecimento geral. Logo, uma Reforma da Previdência a determinar uma idade mínima maior para a aposentadoria é perfeitamente aceitável, mas dentro de parâmetros que não venham a comprometer o próprio direito e a sua essência.

Em um país no qual boa parte dos trabalhadores ainda atua em trabalhos que exigem força física, o critério de idade para fixação de aposentadoria aos 65 anos apenas em face da expectativa de vida pode ser comprometedor, na medida em que a capacidade física em uma idade mais avançada será insuficiente para o exercício de determinadas atividades. Seria necessária, igualmente, a consideração do tipo de trabalho desenvolvido, afinal ninguém 
contrataria um ajudante de pedreiro ou um estivador que não consegue carregar um saco de cimento ou de cereal.

De forma semelhante, deve-se observar que o direito à pensão por morte e também outros benefícios previdenciários fundados no risco também não podem restar inviabilizados, porquanto são estabelecidos em conformidade com uma álea. Logo, se o trabalhador é obrigado ao pagamento de contribuições previdenciárias justamente para assegurar a segurança familiar em razão de falecimento ou mesmo o próprio sustento em face de uma enfermidade que o impede de laborar, não poderia haver justificativa para a limitação na obtenção da prestação social apenas porque há um alto custo na prestação estatal. A pensão por morte não deveria ser estipulada conforme um percentual sobre a quantidade de recolhimentos.

A morte ou enfermidade em virtude de acidentes viários é comum no Brasil. Em decorrência da falta de segurança no trânsito, muitas vezes por ausência do poder público em face de estradas com grande movimento em pistas simples, vias públicas com buracos ou mal asfaltadas e ausência de sinalização, muitas mortes ocorrem com condutores de veículos (principalmente de jovens com motocicletas), de maneira que, ao estabelecer critérios restritivos ao recebimento de pensão por morte, o Estado acaba por prejudicar duplamente os segurados ou seus dependentes, dada a ausência do provedor familiar e pela falta do benefício. Seria conveniente, por exemplo, não a extinção da pensão por morte, mas uma redução do valor do benefício para os filhos que completem 21 anos, mas continuam a estudar.

Com relação à carência (quantidade mínima de contribuições para o recebimento de um benefício) para lograr um auxílio-doença, é certo que dispensá-la ou exigir uma carência muito pequena pode acarretar fraudes na medida em que as pessoas voltam a contribuir ao descobrirem uma enfermidade apenas para o recebimento do benefício. Por outro lado, pode ser punitivo exigir toda a carência necessária para o recebimento do auxílio-doença do trabalhador que possui muitas contribuições, deixou de contribuir em decorrência de desemprego, perdeu a qualidade de segurado, mas voltou a trabalhar com o pagamento de várias contribuições sociais, de maneira que seria mais razoável exigir a metade das contribuições necessárias do período de carência.

Em tempo de Reforma Previdenciária, é necessária atenção especial para que a reserva do possível não seja utilizada para justificar a extinção, redução demasiada ou o 
impedimento na obtenção de direitos que venham a assegurar a dignidade das pessoas, sob pena de retrocesso, de maneira que parâmetros precisam ser estabelecidos tal qual ocorreu com o direito a tratamentos na área da saúde.

\section{CONCLUSÃO}

Sem a pretensão de esgotar o debate acerca do tema, pretendeu-se no presente trabalho demonstrar, ainda que de forma sucinta, a evolução dos direitos fundamentais sociais ao longo do tempo, bem como esclarecer a que se refere a Reserva do Possível.

Tendo em vista que os direitos sociais são reconhecidos como direitos positivos ou prestacionais, evidentemente que consistem num custo econômico-financeiro ao Estado, motivo pelo qual, diante da escassez de recursos do ente estatal, muitas vezes a aplicabilidade desses direitos resta comprometida. Deve-se considerar, com exceção das verbas referentes à saúde e à educação, que a Constituição Federal de 1988 não estabeleceu de maneira específica os meios e os montantes segundo os quais os recursos devem ser aplicados para a efetivação dos direitos sociais.

Tais particularidades conferem aos agentes públicos responsáveis pela formulação e execução de políticas públicas um irrefragável espaço de livre conformação ou discricionariedade, que, em regra, deve ser observado e respeitado por força do princípio democrático, da separação dos poderes e dos princípios orçamentários.

Não obstante, esse poder discricionário, como qualquer outro, não é ilimitado, podendo-se extrair da própria Constituição fundamentos com base nos quais os direitos sociais nela previstos podem ser exigidos mediante invocação do próprio preceito constitucional que o alberga, ainda que se trate de um preceito aberto. Dentre eles, pode-se apontar que, em situação de colisão com outros bens jurídicos, como o direito à vida e à dignidade da pessoa humana, os direitos sociais considerados mais relevantes, mediante regular ponderação, são aptos a fazer emergir o caráter subjetivo e a fundamentalidade dos direitos sociais, conferindo ao seu titular o poder de exigibilidade imediata diante do Poder Público.

Sob outro vértice, a questão do custo dos direitos pode se manifestar como insuficiência de recursos para fazer frente à realização do direito, seja como um impedimento fático ou jurídico, caso em que dará ensejo à reserva do possível. 
A reserva do possível, como dado fático que limita e condiciona a realidade normativa, tem legítima aplicação no campo dos direitos fundamentais sociais, desde que realmente se trate de uma limitação efetiva, e desde que os valores a ela subjacentes se mostrem dignos de prevalecer sobre o nível de realização dos direitos sociais que se lhes contraponha.

Sob perspectiva diversa, a vedação ao retrocesso, como corolário da segurança jurídica, também se constitui em importante limitador das pretensões de redução do âmbito de proteção social já atingido. Em razão da cláusula, o ajuste ou redução pretendida, ao amparo da reserva do possível, deve ter o bem jurídico que lhe dá substrato ponderado com aquele que sustenta o direito social a ser sacrificado, somente devendo prevalecer caso justificável sob o ponto de vista de uma melhor distribuição dos recursos para o atendimento das necessidades sociais, e caso não atinja o núcleo essencial e mínimo do direito.

\section{REFERÊNCIAS}

BARROSO, Luís Roberto. O Direito Constitucional e a efetividade de suas normas: limites e possibilidades da constituição brasileira. 8. ed. Rio de Janeiro: Renovar, 2006,

BOBBIO, Norberto. A Era dos Direitos. Rio de Janeiro: Elsevier, 2004.

BRASIL. Supremo Tribunal Federal. Pleno. Agravo Regimental na Suspensão de Tutela Antecipada $n^{\circ}$ 175/CE. Agravante: União. Agravado: Ministério Público Federal, Clarice Abreu de Castro Neves, Município de Fortaleza e Estado do Ceará. Relator: Ministro Gilmar Mendes, 17 de março de 2010. Votação unânime. Diário Oficial [da] República Federativa do Brasil, Brasília, DF, 30 de abril de 2010 [2010a]. Disponível em:

http://redir.stf.jus.br/paginador/paginador.jsp?docTP=AC\&docID=613301. Acesso em: 19 ago. 2019.

BRASIL. Supremo Tribunal Federal. Pleno. Agravo Regimental na Suspensão de Tutela Antecipada n ${ }^{\circ}$ 361/BA. Agravante: Estado da Bahia. Agravado: Francisco de Pinho dos Santos. Relator: Ministro Cezar Peluso, 23 de junho de 2010. Votação unânime. Diário Oficial [da] República Federativa do Brasil, Brasília, DF, 13 de agosto de 2010. [2010b]. Disponível em: http://redir.stf.jus.br/paginador/paginador.jsp?docTP=AC\&docID=613301. Acesso em: 19 ago. 2019.

BREUS, Thiago Lima. Políticas públicas no Estado Constitucional: problemática da concretização dos direitos fundamentais pela Administração Pública brasileira contemporânea. Belo Horizonte: Fórum, 2007.

CANOTILHO, José Joaquim Gomes. Direito Constitucional. Coimbra: Almedina, 1991. 
CANOTILHO, José Joaquim Gomes. Direito Constitucional e teoria da Constituição. 4. ed. Coimbra: Almedina, 2003.

CAYRES, Giovanna Rossetto Magaroto. A reserva do possível como limite para efetivação dos direitos fundamentais sociais e o mínimo existencial. Revista de Artigos do $1^{\circ}$ Simpósio sobre Constitucionalismo, Democracia e Estado de Direito. Marília, SP, v. 1, n. 1, p. 864877, jan. 2017. Disponível em:

https://revista.univem.edu.br/1simposioconst/article/view/1215. Acesso em: 18 ago. 2019.

COMPARATO, Fábio Konder. A afirmação dos direitos humanos. 3. ed. São Paulo:

Saraiva, 2004.

HOLMES, Stephen; SUNSTEIN, Cass R. The cost of rights. Why liberty depends on taxes. New York - London: W. W. Norton \& Company, 1999.

JOSKOWICZ, Graziela Mayra. A eficácia dos direitos sociais e o controle judicial das políticas públicas. Revista da AGU. Brasília, DF, a. 9, n. 24, abr./jun. 2010. Disponível em: https://seer.agu.gov.br/index.php/AGU/article/view/219/142. Acesso em: 2 set. 2019.

KELBERT, Fabiana Okchsteis. Reserva do Possível e a efetividade dos direitos sociais no direito brasileiro. Porto Alegre: Livraria do Advogado, 2011.

KRELL, Andreas Joachim. Direitos sociais e controle judicial no Brasil e na Alemanha: os descaminhos de um direito constitucional comparado. Porto Alegre: Sergio Antonio Fabris Editor, 2002.

LAFER, Celso. A reconstrução dos direitos humanos. Um diálogo com o pensamento de Hannah Arendt. São Paulo: Companhia das Letras, 1988.

LEDUR, José Felipe. Direitos fundamentais sociais: Efetivação no âmbito da democracia participativa. Porto Alegre: Livraria do Advogado, 2009.

OLSEN, Ana Carolina Lopes. Direitos fundamentais sociais: efetividade frente à reserva do possível. Curitiba: Juruá, 2008.

OTERO, Cleber Sanfelici. Inclusão social da extrema pobreza: direito à cidadania integral e contextualização do mínimo necessário no Brasil. 2011. 444 f. Tese (Doutorado em Direito) Instituição Toledo de Ensino de Bauru, Bauru, SP.

SARLET, Ingo Wolfgang; FIGUEIREDO, Mariana Filchtiner. Reserva do possível, mínimo existencial e direito à saúde: algumas aproximações. In: SARLET, I. W.; TIMM, L. B. (org.). Direitos Fundamentais: orçamento e "reserva do possível". Porto Alegre: Livraria do Advogado.

SARLET, Ingo Wolfgang. A eficácia dos direitos fundamentais: uma teoria geral dos direitos fundamentais na perspectiva constitucional. 11. ed. Porto Alegre: Livraria do Advogado, 2012. 